\title{
Estimates of the steady state growth rates for some European countries
}

\author{
Paolo Casadio a ${ }^{\text {, Antonio Paradiso }}{ }^{\text {b, } *}$, B. Bhaskara Rao ${ }^{c}$ \\ a Intesa Sanpaolo Bank Group, Risk Management, Rome Italy \\ b National Institute for Statistics (ISTAT), Rome, Italy \\ c School of Economics and Finance, University of Western Sydney, Sydney, Australia
}

\section{A R T I C L E I N F O}

\section{Article history:}

Accepted 16 March 2012

\section{JEL classification:}

C22

052

040

\section{Keywords:}

Extended Solow growth model

Trade openness

Human capital

Investment ratio

Steady state growth rate

European countries

\begin{abstract}
A B S T R A C T
This paper estimates the steady state growth rates for the main European countries with an extended version of the Solow (1956) growth model. Total factor productivity is assumed a function of human capital, trade openness and investment ratio. We show that these factors, with some differences, have played an important role to improve the long run growth rates of Italy, Spain, France, UK, and Ireland. A few policies to improve the long-run growth rates for these countries are suggested.
\end{abstract}

(c) 2012 Elsevier B.V. All rights reserved.

\section{Introduction}

In the Solow (1956) growth model the long-run equilibrium growth of output (expressed in per worker terms) is determined by total factor productivity (TFP). TFP is usually estimated as a residual from the growth accounting framework of Solow (1957) and for this reason is also known as the Solow Residual (SR). Endogenous Growth Models (ENGMs) identify factors on which the TFP/SR may depend. Although there is a large number of cross-country empirical works based ENGMs, empirical work with country-specific time series data is limited. ${ }^{1}$ In addition, the major part of these studies is on the developing countries ${ }^{2}$ and very few on the matured industrial economies. ${ }^{3}$ Therefore, it is not known what are the long run growth rates of such industrialized countries and what are the important factors on which their TFPs depend. This paper aims to fill this gap but uses an extended Solow (1956) growth model for this purpose. We estimate the long run growth rates for a selected group of European

\footnotetext{
* Corresponding author.

E-mail addresses: paolo.casadio@yahoo.it (P. Casadio), anto_paradiso@hotmail.com (A. Paradiso), raob123@bigpond.com (B.B. Rao).

${ }^{1}$ Greiner et al. (2005) is one of the few attempts to estimate endogenous ENGMs with country-specific time series data. More recent studies are Rao (2010a) and Rao (2010b) for example.

2 See Rao and Cooray (2011).

${ }^{3}$ See for example Paradiso and Rao (2011) for a study on Italy.
}

countries: Italy, France, UK, Spain, and Ireland and our methodology can also be used to estimate the long run growth rates for other countries.

In the empirical work on the ENGMs many potential determinants of the long-run growth have been used although it is difficult to develop theoretical frameworks to justify each and every potential determinant. For example, Durlauf et al. (2005) make a list of more than 100 potential growth determinants in the empirical works. However, Jones (1995) cited no more than 10 potential determinants of the long-run growth such as physical investment rate, human capital, export share, government consumption etc. ${ }^{4}$ Due to limited sample size (50 observations) in the country specific time series data, only a few such potential explanatory variables can be considered. Although we experimented with several variables, we found that trade openness ${ }^{5}$ (TRADE), an index of human capital (HKI) and investment ratio (IRAT) are adequate to explain TFP in our selected countries. After having estimated our extended growth model, we estimate the steady state growth rate (SSGR) defined as a situation in which the rate of growth of physical capital (expressed in per capita

\footnotetext{
${ }^{4}$ Levine and Renelt (1992), using the extreme bounds analysis, have found that only the investment ratio is a robust explanatory variable of growth.

${ }^{5}$ Trade openness (or short: openness) measure is based on the share of nominal exports and imports in GDP. Several measures of openness have been used in the empirical growth literature. The ratio between exports and imports and GDP has increasingly become the variable of choice in empirical growth analysis. See for example Bergheim (2008) on this point.
} 
worker terms) goes to zero and output per worker grows at the same rate of TFP $\left(\Delta \ln y^{*}=g\right)$. This permits us to make a sensitivity analysis to understand which variables have to be stimulated to favor growth.

The paper is organized as follows. In Section 2 we discuss the extended Solow model and develop our specification used in estimations. Section 3 presents a description of the countries' characteristics. Section 4 shows the estimation results for Italy, Spain, France, UK, and Ireland. Section 5 concludes.

\section{Specification}

The starting point is the steady state solution for the level of output in the Solow (1956) growth model and this is:

$y^{*}=\left(\frac{s}{d+g+n}\right)^{\frac{\alpha}{1-\alpha}} A$

where $y^{*}(=Y / L)$ is the steady state level of income per worker, $s=$ the ratio of investment to income, $d=$ depreciation rate of capital, $g=$ the rate of technical progress, $n=$ the rate of growth of labour, $A=$ the stock of knowledge and $\alpha=$ the exponent of capital in the Cobb-Douglas production function with constant returns (see below). This implies that the steady state rate of growth of per worker output (SSGR), assuming that all other ratios and parameters are constant, is simply TFP because:

$\Delta \ln y^{*}=S S G R=\Delta \ln A=T F P$

However, since the determinants of TFP are not known and are exogenous in the Solow (1956) growth model, the Solow model is also known as the exogenous growth model. The new growth theories based on ENGM use optimization framework and suggest several potential determinants of TFP. However, to the best of our knowledge there is no ENGM which rationalizes that TFP depends on more than one or two selected variables. We take the view that the Solow model can be extended by making TFP a function of a few of the determinants identified by the ENGMs. For example, if the findings of Levine and Renelt (1992, see footnote 4) are valid, then TFP depends only on the investment ratio in spite of the findings by Durlauf et al. (2005) and Jones (1995).

We extend the Solow model as follows. Note that the SSGR can be estimated by estimating the production function. The production function can also be extended by assuming that the stock of knowledge $(A)$ depends on some important variables identified by the ENGMs. We start with the well-known Cobb-Douglas production function with constant returns:

$Y_{t}=A_{t} K_{t}^{\alpha} L_{t}^{(1-\alpha)}$

Following Rao (2010b) and Paradiso and Rao (2011) we assume the following general evolution for the stock of knowledge $A$ is as follows ${ }^{6}$ :

$A_{t}=A_{0} e^{\left(a \cdot T+\varpi R_{t} \cdot T+\gamma_{1} Z_{t}+\gamma_{2} Z_{t}^{2}+\varphi W_{t}+\vartheta \ln S_{t} \cdot T\right)} X_{t}^{\delta}$

where Tis time and $R, Z, W$, Sand Xare variables on which TFP depends in different ways. This can be explained by taking the logs of Eq. (4) with lower case letters denoting the logs as:

$a_{t}=a_{0}+a \cdot T+\varpi R_{t} \cdot T+\gamma_{1} Z_{t}+\gamma_{2} Z_{t}^{2}+\varphi W_{t}+\vartheta \ln S_{t} \cdot T+\delta \ln X_{t}$

\footnotetext{
6 This approach and specification are based on empirical considerations and our specification (5) gave the best empirical results. We are not aware of any ENGM in which the functional form of the determinants of TFP is well established with theoretical insights.
}

Taking the first difference gives:

$$
\begin{aligned}
\Delta a_{t}=T F P=a & +\varpi \Delta R_{t} \cdot T+\varpi R_{t-1}+\gamma_{1} \Delta Z_{t}+\gamma_{2} \Delta Z_{t}^{2}+\varphi \Delta W_{t} \\
& +\vartheta \Delta \ln S_{t} \cdot T+\vartheta \ln S_{t-1}+\delta \Delta \ln X_{t}
\end{aligned}
$$

Eq. (6) captures the actual growth rate of output due to changes in variables, other than factor accumulation. The effects of these other variables may be trended and linear, some of which are transitory and some permanent $\left(a+\varpi \Delta R_{t} \cdot T+\varpi R_{t-1}\right)$ but nonlinear $\left(\gamma_{1} \Delta Z_{t}+\right.$ $\gamma_{2} \Delta Z_{t}^{2}$ and $\left.\delta \Delta \ln X_{t}\right)$ or transitory and linear $(\Delta W)$ or nonlinear but with some transitory and some permanent $\left(\vartheta \Delta \ln S_{t} \cdot T+\vartheta \ln S_{t-1}\right)$. Our choice of the variables is made on the basis of empirical considerations.

The steady state growth rate (SSGR) is defined as the situation when all differences go to zero:

$$
\therefore S S G R=a+\varpi R_{t-1}+\vartheta \ln S_{t-1}
$$

The higher are R and S levels, and higher is the SSGR.

\section{Countries' characteristics}

In Table 1 we present the country characteristics of the key variables used in this study and we have divided the sample into two parts 1960-1985 and 1986-2010. The first period was in general characterized by high growth for all countries, whereas in the second there are some differences in their growth performance. In the second sample the growth rates in Italy, France, and Spain have decreased. This decline is particularly accentuated for Italy. For UK the growth remains somewhat stable and in Ireland growth has increased. In describing the main macroeconomic characteristics of these countries we also report some country specific events to justify later the use of dummy variables in their estimation.

The prolonged period of sustained growth in Italy comprised between the end of World War II and the late of 1960s was called the "Italian economic miracle" ("Il miracolo economico Italiano"). The last years of 1960s and the beginning of 1970s were characterized by a working-class struggle. The events of these years and the wage bargaining agreements that went into effect in 1970 determine the beginning of a new regime in the wage determination process (Modigliani et al., 1986). The investment ratio slightly decreased in the second sample, even if it is above $20 \%$ despite of the recent recession of 2008-2009. Employment accelerated in the second sample, in particular after the mid-1990s due to significant labour market reforms in the 1990s (Schindler, 2009). Trade openness grew sharply in the second sample, in particular after the 1990s. The average years of education is the lowest among the countries considered, even if the average value in the period 1960-1985 was larger than in France and Spain.

Spain's economy was characterized by huge growth in the period 1960-1985, and in the second sample growth slowed down even though it was above the growth rates in Italy, UK, and France. To illustrate this performance we have to consider two important changes in the Spanish economy. The first is in 1978 with the introduction of the Constitution and the beginning of the de-facto democracy in Spain. The second is in 1994 when labour market reforms were introduced. These reforms allowed private employment agencies to operate freely, and introduced flexibility into firing costs and bargaining process (Dolado et al., 2002). According to Boldrin et al. (2010), the period after the reforms was characterized by a spectacular increase in employment and a small gain in the productivity. The investment ratio is well above $20 \%$ and grew in the second sample. Employment has also increased after the labour market reforms. Trade openness tripled from $17 \%$ to $51 \%$ and Spain became more opened than France and Italy. Spain's education performance is the result of the political 
Table 1

Country characteristics.

\begin{tabular}{|c|c|c|c|c|c|c|c|c|c|c|}
\hline \multirow[t]{2}{*}{ Country } & \multicolumn{2}{|c|}{ Average $\Delta \ln y$} & \multicolumn{2}{|c|}{ Average $(I / Y)$} & \multicolumn{2}{|c|}{ Average $\Delta \ln L$} & \multicolumn{2}{|c|}{ Average TRADE } & \multicolumn{2}{|l|}{ Average $H K I$} \\
\hline & 1960-1985 & 1986-2010 & 1960-1985 & 1986-2010 & 1960-1985 & $1986-2010$ & 1960-1985 & 1986-2010 & 1960-1985 & 1986-2010 \\
\hline Italy & $4.05 \%$ & $1.34 \%$ & $22.76 \%$ & $20.01 \%$ & $0.28 \%$ & $0.54 \%$ & $25.67 \%$ & $46.46 \%$ & 5.96 & 8.41 \\
\hline Spain & $4.50 \%$ & $2.80 \%$ & $21.18 \%$ & $24.56 \%$ & $-0.29 \%$ & $1.94 \%$ & $17.43 \%$ & $50.61 \%$ & 4.98 & 8.54 \\
\hline UK & $2.32 \%$ & $2.23 \%$ & $14.93 \%$ & $16.51 \%$ & $0.11 \%$ & $0.69 \%$ & $29.60 \%$ & $51.68 \%$ & 7.34 & 8.71 \\
\hline Ireland & $3.98 \%$ & $4.67 \%$ & $25.47 \%$ & $20.82 \%$ & $0.01 \%$ & $0.20 \%$ & $57.29 \%$ & $144.94 \%$ & 9.21 & 10.92 \\
\hline France & $3.99 \%$ & $1.90 \%$ & $20.63 \%$ & $19.12 \%$ & $0.36 \%$ & $0.63 \%$ & $24.52 \%$ & $48.34 \%$ & 5.37 & 8.90 \\
\hline
\end{tabular}

change that started in the 1970s. Education started increasing from a very low level of 3.3 average years of education in the 1960s and reached a value of 10.4 by 2010 , which is above Italy's value and in line with France.

UK exhibits a somewhat stable GDP growth in the two sample periods. Investment ratio increased slightly in the second sample. Employment increased in the second sample, in particular in the second half of 1980 . Trade openness passed from an average of 30\% in the $1960-1985$ to a value of $52 \%$ in the $1986-2010$ period. UK started from a high value in education in 1960 (6.3 average years of schooling) and increased to 9.6 in 2010, with an average value of 8.7 over the sample $1986-2010$.

Ireland's growth rate was high in the 1960s with the exception of the 1965-1966. In these two years its average growth rate was of $1.4 \%$ against an average growth rate of $4 \%$ in the previous 5 years. This growth was sustained during the period examined, and increased during 1986-2010. However, during 2008-2009 there was a banking crisis and a deep recession. In these two years Ireland experienced its worst financial crisis to date (O'Sullivan and Kennedy, 2010). The GDP growth fell to $3.6 \%$ in 2008 and $7.9 \%$ in 2009. Investment ratio has declined in the second sample even though it was above $20 \%$. Ireland is one of the most open economies in the OECD area after Belgium, Hungary, Luxembourg, and Slovak Republic. The time-series data reveal a growing trend towards openness after the 1970s and since its membership in the European Economic Community. Another characteristic of Ireland is the steep rise in the educational attainment since the 1990s, which brought Ireland in line with countries that have high historical level of education. According to the Barro and Lee (2010) dataset, Ireland is a leading country in education, in line with schooling levels in Sweden, Germany and the Republic of Korea.

For France the 1960s and in particular in the second half of 1960s was a period of high economic growth. The average growth rate in the period $1965-1970$ was $5.4 \%$. This performance was the result of government investment programs and industrial policy that promoted large-scale economic projects in the fields of high-tech aeronautics, information technology (IT), and telecommunication (Estrin and Holmes, 1983). In addition, this period was characterized by large immigration to sustain the production by French manufactures (in particular in the car industry). Employment accelerated in particular in the late of 1990s partially due to a shift in the demand for labour (Pisani-Ferry, 2003). Investment ratio slightly decreased from an average value of $21 \%$ in the first sample to $19 \%$ in the second sample. Trade openness increased strongly as other countries investigated. Starting from a lower education value, France passes Italy and UK over the years.

\section{Estimation results}

Data from 1960 to 2010 are used to estimate the production function (3) augmented with (4) for these five European countries. Definitions of variables and sources of data are in Appendix A. Two cointegration techniques are used to estimate the long run relationships viz., the Phillips and Hansen (1990) Fully Modified OLS (FMOLS) and Stock and Watson (1993) Dynamic OLS (DOLS). These estimators deal with the problem of second-order asymptotic bias arising from serial correlation and endogeneity and are asymptotically equivalent; see Gonzalo (1994).

Our estimation strategy is the following. We first estimate the long-run relationships with these two methods. If these techniques show plausible and similar results, we identify the existence of cointegrating relationship through the Engle-Granger (EG) residual test. If the test confirms the existence of cointegration, we construct an Error Correction Model (ECM) with the long-run relationship and we study the factor loading and the tests of correct specification (normality, absence of autocorrelation, and no heteroskedasticity in the residuals). If all these conditions are satisfied, we conclude that there is a cointegrating relationship. To conserve space only reasonable final results are reported in the tables. In estimations some dummies are also used to account for a few outliers. Details of these are in Section 3 and are briefly summarized in the Data appendix.

\subsection{Italy}

According to Eq. (4), for Italy we selected the following ${ }^{7}$ :

$X_{t}=T R A D E, Z_{t}=H K I, R_{t}=I R A T_{t}$

This indicates that Italian economy was driven mainly by the dynamics of trade, human capital and investment ratio. Results for 1960-2010 are reported in Table 2 below. Both the estimates of this equation are satisfactory in that all of the coefficients are correctly signed and statistically significant. The EG residual test confirms the existence of a cointegrating relationship, whereas diagnostic tests on ECM residuals are not serially correlated, normally distributed, and not heteroskedastic. The coefficient representing the share of profits seems a bit high, but it is plausible.

The corresponding SSGR and the actual rate of growth per worker output are presented in Fig. 1 below. The value of SSGR corresponds to the IRAT series multiplied for its coefficient. SSGR is somewhat stable around $0.3 \%$ to $0.4 \%$. This suggests that the long run Italian growth rate is stagnant and can be seen from the actual growth rate since the mid 1990s. Earlier positive growth rates seem to be due to positive factor accumulation and not due to TFP. Our estimates suggest that to reach a SSGR of $0.5 \%$ it is necessary to increase IRAT to a value close to $30 \%$, a value very close to the IRAT in the early years of 1960 s.

\subsection{Spain}

For Spain the best results are obtained when it is assumed that:

$Z_{t}=H K I, R_{t}=H K I_{t}$

Spain's growth dynamic seems to be driven mainly by education. This is the result of a political strategy that started in the 1970s.

\footnotetext{
${ }^{7}$ Our selection for $X, Z$ and $R$ variables for Italy and other countries is based on empirical considerations.
} 
Table 2

Results for Italy: 1960-2010.

\begin{tabular}{|c|c|c|}
\hline \multicolumn{3}{|c|}{$\ln y_{t}=$ Intercept $+\alpha \ln k_{t}+\gamma_{1} H K I_{t}+\gamma_{2} H K I_{t}^{2}+\varpi I R A T_{t} \cdot T+\delta \ln T R A D E_{t}$} \\
\hline & FMOLS & DOLS \\
\hline \multirow[t]{3}{*}{ Intercept } & -2.770 & -2.541 \\
\hline & $(0.147)$ & $(0.591)$ \\
\hline & [18.784] & [4.301] \\
\hline \multirow[t]{3}{*}{$\ln k$} & 0.630 & 0.754 \\
\hline & $(0.026)$ & $(0.138)$ \\
\hline & {$[23.800]$} & [5.443] \\
\hline \multirow[t]{3}{*}{$\ln T R A D E$} & 0.308 & 0.206 \\
\hline & $(0.015)$ & $(0.100)$ \\
\hline & [20.653] & [2.046] \\
\hline \multirow[t]{3}{*}{ HKI } & 0.373 & 0.324 \\
\hline & $(0.023)$ & $(0.116)$ \\
\hline & [15.919] & [2.794] \\
\hline \multirow[t]{3}{*}{$H K I^{2}$} & -0.029 & -0.023 \\
\hline & $(0.001)$ & $(0.008)$ \\
\hline & [21.764] & [3.044] \\
\hline \multirow[t]{3}{*}{$\operatorname{IRAT} \cdot T$} & 0.017 & 0.007 \\
\hline & $(0.002)$ & $(0.002)$ \\
\hline & [6.674] & [2.955] \\
\hline \multirow[t]{3}{*}{$\lambda$} & -0.700 & \\
\hline & $(0.338)$ & \\
\hline & {$[2.071]$} & \\
\hline EG residual test & $-6.697^{* * *}$ & \\
\hline $\mathrm{LM}(1)$ test ( $p$-value) & 0.449 & \\
\hline $\mathrm{LM}(2)$ test ( $p$-value) & 0.413 & \\
\hline LM(4) test ( $p$-value) & 0.340 & \\
\hline JB test ( $p$-value) & 0.768 & \\
\hline BPG test ( $p$-value) & 0.618 & \\
\hline
\end{tabular}

Notes: Standard errors are reported in ( ) brackets, whereas t-statistics in [ ] brackets. *, ${ }^{* *},{ }^{* * *}$ denotes significance at $10 \%, 5 \%$, and $1 \%$, respectively. FMOLS = Fully Modified Ordinary Least Squares; DOLS = Dynamic Ordinary Least Squares. EG = Engle-Granger $t$-test for cointegration. $\lambda$, factor loading in the ECM. BPG, Breusch-Pagan-Godfrey heteroskedasticiy test; JB, Jarque-Bera normality test, LM, Bresuch-Godfrey serial correlation LM test. FMOLS uses Newey-West automatic bandwidth selection in computing the long-run variance matrix. In the DOLS leads and lags are selected according to SIC criteria. The standard errors for the DOLS estimation are calculated using the Newey-West correction. A dummy for recession in 1975 (due to oil price shock) is added in ECM formulation.

Spanish politicians laid the ground stone for the increase in education even before the end of the Franco dictatorship. Other important reforms were the University Reform Act of 1983 and University Act of 2001. The result was a huge increase in average years of education among the Spanish population. The results for Spain are reported in Table 3.

The resulting SSGR shows a value equal to $1 \%$ towards the end of the sample, but more interestingly SSGR for Spain shows a continuous upward pattern (Fig. 2). Our estimates show that if the current level of schooling years of 10.4 increases to 11.9 years, SSGR in Spain increases by an additional $0.2 \%$ points. $^{8}$

\subsection{United Kingdom}

For the UK the following formulation for Eq. (4) gave the best results:

$Z_{t}=H K I, R_{t}=I R A T_{t}$

The investment ratio (IRAT) seems to be the most influential determinants of the long-run growth. Results are in Table 4.

From the plots of actual growth rate and SSGR in Fig. 3, it can be seen that SSGR oscillates around $1.3-1.4 \%$ in the last 15 years. This may be due to the fluctuations in the investment ratio. To increase the SGGR to a value above $1.6 \%$, it is necessary to increase the

\footnotetext{
${ }^{8}$ In Germany the average years of schooling is near 12 years.
}

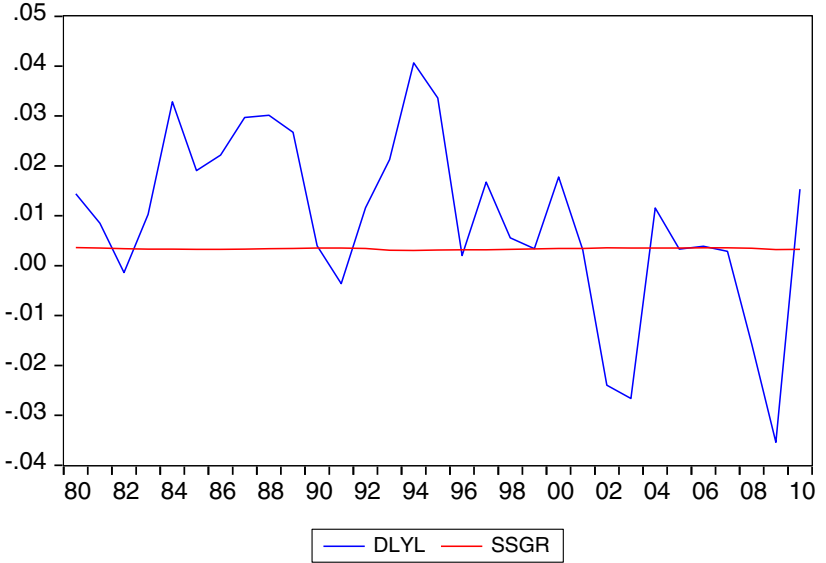

Fig. 1. Actual growth per worker and SSGR for Italy.

investment ratio from its current value of $16 \%$ to $20 \%$ and also minimize fluctuations in this ratio. A graph of UK IRAT is in Appendix A.

\subsection{Ireland}

For Ireland the following formulation of Eq. (4) gave the best results.

$Z_{t}=H K I, R_{t}=H K I_{t}, S_{t}=T R A D E$

Ireland is the only country for which both variables TRADE and HKI enter as the determinants of SSGR. Ireland is one of the most open economies in the world and its trade ratio has been well above $100 \%$ from the 1990s. The impressive gains in labour productivity experienced since the 1990s were underpinned by a steep rise in educational attainment of the working age population. The average years of education in 2010, according to Barro and Lee (2010) dataset is consistent with the level in Sweden, Germany and Republic of Korea (countries with historical high values in education). Estimation results are reported in Table 5.

Ireland's SSGR is well above $2.5 \%$ and shows an accentuated upward trend in Fig. 4 due to impressive gains in productivity. Although SSGR is still very high in Ireland, our estimates suggest that further improvements can be made by improving education through job training schemes or by increasing the openness of the

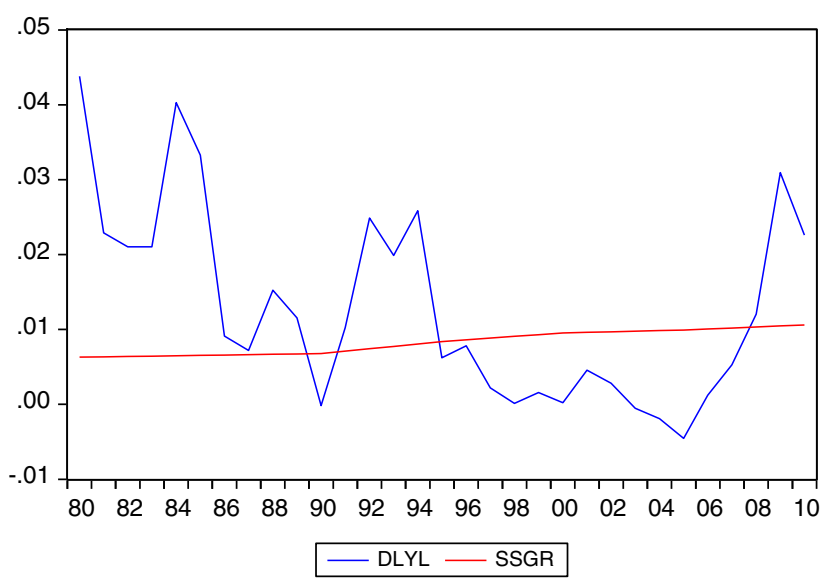

Fig. 2. Actual growth per worker and SSGR for Spain. 
Table 3

Results for Spain: 1960-2010.

\begin{tabular}{|c|c|c|}
\hline \multicolumn{3}{|c|}{$\ln y_{t}=$ Intercept $+\alpha \ln k_{t}+\gamma_{1} H K I_{t}+\gamma_{2} H K I_{t}^{2}+\varpi H K I_{t} \cdot T$} \\
\hline & FMOLS & DOLS \\
\hline \multirow[t]{3}{*}{ Intercept } & -4.236 & -5.381 \\
\hline & $(0.595)$ & $(0.388)$ \\
\hline & [7.124] & [13.880] \\
\hline \multirow[t]{3}{*}{$\ln k$} & 0.407 & 0.174 \\
\hline & $(0.117)$ & $(0.073)$ \\
\hline & [3.465] & {$[2.368]$} \\
\hline \multirow[t]{3}{*}{$H K I \cdot T$} & 0.001 & 0.002 \\
\hline & $(0.000)$ & $(0.000)$ \\
\hline & [1.681] & [4.227] \\
\hline \multirow[t]{3}{*}{$H K I$} & 0.477 & 0.683 \\
\hline & $(0.073)$ & $(0.064)$ \\
\hline & {$[6.330]$} & {$[10.584]$} \\
\hline \multirow[t]{3}{*}{$H K I^{2}$} & -0.032 & -0.050 \\
\hline & $(0.007)$ & $(0.006)$ \\
\hline & [4.891] & [8.759] \\
\hline \multirow[t]{3}{*}{$\lambda$} & -0.196 & \\
\hline & $(0.078)$ & \\
\hline & [2.520] & \\
\hline EG residual test & $-6.071^{* * *}$ & \\
\hline LM(1) test ( $p$-value) & 0.760 & \\
\hline LM(2) test ( $p$-value) & 0.523 & \\
\hline LM(4) test ( $p$-value) & 0.800 & \\
\hline JB test ( $p$-value) & 0.550 & \\
\hline BPG test ( $p$-value) & 0.078 & \\
\hline
\end{tabular}

Notes: Standard errors are reported in ( ) brackets, whereas t-statistics in [ ] brackets. *, ${ }^{* *},{ }^{* * *}$ denotes significance at $10 \%, 5 \%$, and $1 \%$, respectively. FMOLS $=$ Fully Modified Ordinary Least Squares; DOLS = Dynamic Ordinary Least Squares. EG = Engle-Granger $t$-test for cointegration. $\lambda$, factor loading in the ECM. BPG, Breusch-Pagan-Godfrey heteroskedasticiy test; JB, Jarque-Bera normality test, LM, Bresuch-Godfrey serial correlation LM test. FMOLS uses Newey-West automatic bandwidth selection in computing the long-run variance matrix. In the DOLS leads and lags are selected according to SIC criteria. The standard errors for the DOLS estimation are calculated using the Newey-West correction. A dummy for 1994 labour market reform (see for detail Appendix A) is added in ECM formulation together with a dummy for the second oil shock (1978).

markets. For example, an increase of TRADE by $5 \%$ will increase SSGR by $0.1 \%$.

\subsection{France}

For France the following formulation of Eq. (4) gave the best results.

$X_{t}=T R A D E, R_{t}=H K I_{t}, Z_{t}=\ln \left(H K I_{t}\right)$

Like for Spain, the main driver of SSGR appears to be the education. The results are reported in Table 6.

France's SSGR in Fig. 5 shows that although it is below the 1\%, it shows an upward trend. To reach a value close to $1 \%(0.9 \%)$, it is necessary to increase the average years of education by 1.5 years from its actual value of 10.5 years to 12 years in Germany.

\section{Conclusions}

In this paper we showed that the Solow growth model can be extended and used to estimate country specific SSGRs. In empirical works this is done so far mainly for the developing countries (see for example Rao, 2010a; Rao and Vadlamannati, 2011a, 2011b). We showed that this can be also done for the developed countries. In our study we estimated SSGRs for 5 developed European countries who benefited from three long-run factors viz., trade openness (TRADE), human capital index (HKI), and investment to GDP ratio (IRAT). Our results showed that these factors are significant in these countries for their long-run growth with some differences. We have
Table 4

Results for UK: 1960-2010.

\begin{tabular}{|c|c|c|}
\hline \multicolumn{3}{|c|}{$\ln y_{t}=$ Intercept $+\alpha \ln k_{t}+\gamma_{1} H K I_{t}+\gamma_{2} H K I_{t}^{2}+\varpi I R A T_{t} \cdot T$} \\
\hline & FMOLS & DOLS \\
\hline \multirow[t]{3}{*}{ Intercept } & -4.541 & -4.512 \\
\hline & $(0.655)$ & $(0.859)$ \\
\hline & [6.932] & [5.253] \\
\hline \multirow[t]{3}{*}{$\ln k$} & 0.482 & 0.495 \\
\hline & $(0.083)$ & $(0.082)$ \\
\hline & [5.820] & [6.016] \\
\hline \multirow[t]{3}{*}{$\operatorname{IRAT} \cdot T$} & 0.081 & 0.075 \\
\hline & $(0.006)$ & $(0.008)$ \\
\hline & [13.695] & [9.745] \\
\hline \multirow[t]{3}{*}{$H K I$} & 0.495 & 0.540 \\
\hline & $(0.091)$ & $(0.106)$ \\
\hline & [5.446] & {$[5.070]$} \\
\hline \multirow[t]{3}{*}{$H K I^{2}$} & -0.033 & -0.038 \\
\hline & $(0.004)$ & $(0.003)$ \\
\hline & [7.273] & [11.127] \\
\hline \multirow[t]{3}{*}{$\lambda$} & -0.341 & \\
\hline & $(0.145)$ & \\
\hline & [2.350] & \\
\hline EG residual test & $-5.246^{* *}$ & \\
\hline $\mathrm{LM}(1)$ test ( $p$-value) & 0.918 & \\
\hline LM(2) test ( $p$-value) & 0.178 & \\
\hline LM(4) test ( $p$-value) & 0.463 & \\
\hline JB test ( $p$-value) & 0.777 & \\
\hline BPG test ( $p$-value) & 0.426 & \\
\hline
\end{tabular}

Notes: Standard errors are reported in ( ) brackets, whereas $t$-statistics in [ ] brackets. * ${ }^{* *},{ }^{* * *}$ denotes significance at $10 \%, 5 \%$, and $1 \%$, respectively. FMOLS = Fully Modified Ordinary Least Squares; DOLS = Dynamic Ordinary Least Squares. EG = Engle-Granger $t$-test for cointegration. $\lambda$, factor loading in the ECM. BPG, Breusch-Pagan-Godfrey heteroskedasticiy test; JB, Jarque-Bera normality test, LM, Bresuch-Godfrey serial correlation LM test. FMOLS uses Newey-West automatic bandwidth selection in computing the long-run variance matrix. In the DOLS leads and lags are selected according to SIC criteria. The standard errors for the DOLS estimation are calculated using the Newey-West correction. A dummy for 2008 financial crisis is added in ECM formulation.

computed the SSGRs for these countries and found that IRAT explains the SSGR dynamics for Italy and UK, HKI for Spain and France and HKI and TRADE for Ireland.

Using these estimates of SSGR, we suggested policies to improve the SSGRs for these countries. For example, for Italy to reach a SSGR of $0.5 \%$ it is necessary to increase IRAT to a value close to $30 \%$. For Spain our estimates show that if the current level of schooling years of 10.4 increases to 11.9 years, SSGR in Spain increases by an additional $0.2 \%$ points. A similar policy can also be implemented in France. For this country, to reach a value close to $1 \%(0.9 \%)$, it is necessary to increase the average years of education by 1.5 years from its actual value of 10.5 years

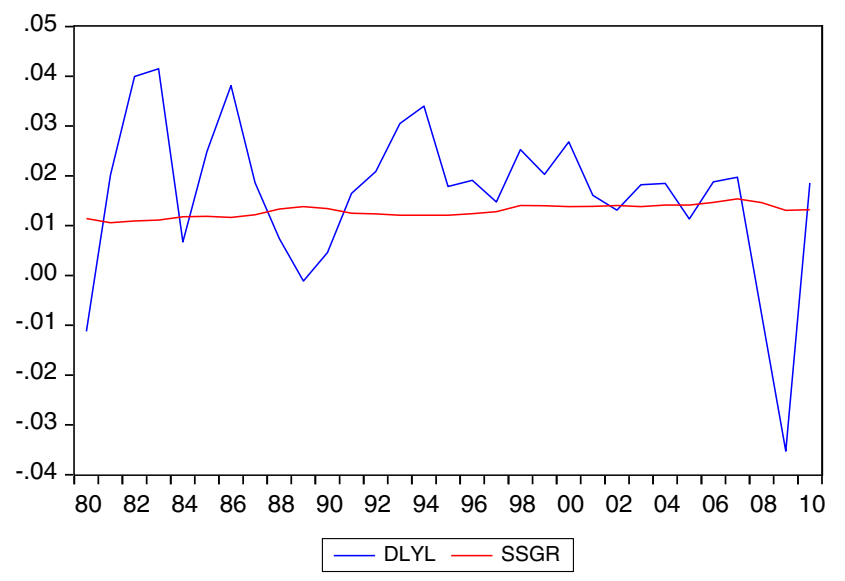

Fig. 3. Actual growth per worker and SSGR for UK. 
Table 5

Results for Ireland: 1960-2010.

\begin{tabular}{|c|c|c|}
\hline \multicolumn{3}{|c|}{$\ln y_{t}=$ Intercept $+\alpha \ln k_{t}+\gamma_{1} H K I_{t}+\gamma_{2} H K I_{t}^{2}+\varpi H K I_{t} \cdot T+\vartheta \ln T R A D E_{t} \cdot T$} \\
\hline & FMOLS & DOLS \\
\hline \multirow[t]{3}{*}{ Intercept } & -9.663 & -9.489 \\
\hline & $(0.503)$ & $(2.149)$ \\
\hline & [19.212] & [4.415] \\
\hline \multirow{3}{*}{$\ln k$} & 0.242 & 0.363 \\
\hline & $(0.052)$ & $(0.175)$ \\
\hline & [4.639] & [2.071] \\
\hline \multirow[t]{3}{*}{$H K I \cdot T$} & 0.003 & 0.003 \\
\hline & $(0.000)$ & $(0.000)$ \\
\hline & [12.446] & [8.794] \\
\hline \multirow[t]{3}{*}{$\ln T R A D E \cdot T$} & 0.004 & 0.007 \\
\hline & $(0.001)$ & $(0.002)$ \\
\hline & [4.038] & [4.423] \\
\hline \multirow[t]{3}{*}{ HKI } & 1.355 & 1.464 \\
\hline & $(0.079)$ & $(0.291)$ \\
\hline & {$[17.071]$} & [5.024] \\
\hline \multirow[t]{3}{*}{$H K I^{2}$} & -0.073 & -0.079 \\
\hline & $(0.004)$ & $(0.014)$ \\
\hline & [17.071] & [5.800] \\
\hline \multirow[t]{3}{*}{$\lambda$} & -0.932 & \\
\hline & $(0.131)$ & \\
\hline & [7.161] & \\
\hline EG residual test & $-5.812^{* * *}$ & \\
\hline LM(1) test ( $p$-value) & 0.460 & \\
\hline $\operatorname{LM}(2)$ test ( $p$-value) & 0.555 & \\
\hline LM(4) test ( $p$-value) & 0.662 & \\
\hline JB test ( $p$-value) & 0.288 & \\
\hline BPG test ( $p$-value) & 0.716 & \\
\hline
\end{tabular}

Notes: Standard errors are reported in ( ) brackets, whereas t-statistics in [ ] brackets. *, ${ }^{* *},{ }^{* * *}$ denotes significance at $10 \%, 5 \%$, and $1 \%$, respectively. FMOLS $=$ Fully Modified Ordinary Least Squares; DOLS = Dynamic Ordinary Least Squares. EG = Engle-Granger $t$-test for cointegration. $\lambda$, factor loading in the ECM. BPG, Breusch-Pagan-Godfrey heteroskedasticiy test; JB, Jarque-Bera normality test, LM, Bresuch-Godfrey serial correlation LM test. FMOLS uses Newey-West automatic bandwidth selection in computing the long-run variance matrix. In the DOLS leads and lags are selected according to SIC criteria. The standard errors for the DOLS estimation are calculated using the Newey-West correction. A dummy for 2008 financial crisis is added in ECM formulation.

to 12 years. In UK, to increase the SGGR to a value above $1.6 \%$, it is necessary to increase the investment ratio from its current value of $16 \%$ to $20 \%$ and also minimize fluctuations in this ratio. Although SSGR is still very high in Ireland, our estimates suggest that an increase of TRADE by $5 \%$ will increase its SSGR by $0.1 \%$. Note that these are long run and permanent growth effects of implementing these policies in contrast to the well known estimates by Barro $(1996,1998)$, which are actually transient growth rates. Therefore, our estimates of these growth rates will be smaller than Barro's estimates.

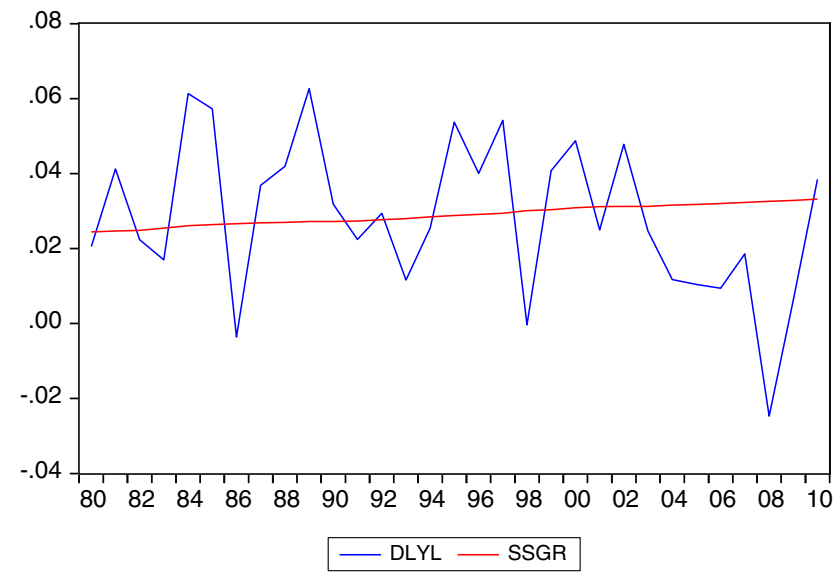

Fig. 4. Actual growth per worker and SSGR for Ireland.
Table 6

Results for France: 1960-2010.

\begin{tabular}{|c|c|c|}
\hline \multicolumn{3}{|c|}{$\ln y_{t}=$ Intercept $+\alpha \ln k_{t}+\gamma_{1} \ln \left(H K I_{t}\right)+\gamma_{2}\left(\ln \left(H K I_{t}\right)\right)^{2}+\varpi H K I_{t} \cdot T+\delta \ln T R A D E_{t}$} \\
\hline & FMOLS & DOLS \\
\hline \multirow[t]{3}{*}{ Intercept } & -6.623 & -7.421 \\
\hline & $(0.854)$ & $(1.432)$ \\
\hline & [7.751] & [5.185] \\
\hline \multirow[t]{3}{*}{$\ln k$} & 0.323 & 0.189 \\
\hline & $(0.077)$ & $(0.129)$ \\
\hline & [4.182] & {$[1.471]$} \\
\hline \multirow[t]{3}{*}{$\ln T R A D E$} & 0.291 & 0.310 \\
\hline & $(0.024)$ & $(0.017)$ \\
\hline & [11.933] & [18.080] \\
\hline \multirow[t]{3}{*}{$\ln H K I$} & 4.635 & 5.328 \\
\hline & $(0.722)$ & $(1.172)$ \\
\hline & [6.417] & {$[4.548]$} \\
\hline \multirow[t]{3}{*}{$(\ln H K I)^{2}$} & -1.218 & -1.440 \\
\hline & $(0.194)$ & $(0.305)$ \\
\hline & [6.283] & {$[4.724]$} \\
\hline \multirow[t]{3}{*}{$H K I \cdot T$} & 0.001 & 0.001 \\
\hline & $(0.000)$ & $(0.000)$ \\
\hline & [3.189] & [5.085] \\
\hline \multirow[t]{3}{*}{$\lambda$} & -0.267 & \\
\hline & $(0.121)$ & \\
\hline & [2.209] & \\
\hline EG residual test & $-5.697^{* *}$ & \\
\hline LM(1) test ( $p$-value) & 0.184 & \\
\hline LM(2) test ( $p$-value) & 0.151 & \\
\hline LM(4) test ( $p$-value) & 0.110 & \\
\hline JB test ( $p$-value) & 0.545 & \\
\hline BPG test ( $p$-value) & 0.379 & \\
\hline
\end{tabular}

Notes: Standard errors are reported in ( ) brackets, whereas t-statistics in [ ] brackets. *, $*^{* *},{ }^{* * *}$ denotes significance at $10 \%, 5 \%$, and $1 \%$, respectively. FMOLS = Fully Modified Ordinary Least Squares; DOLS $=$ Dynamic Ordinary Least Squares. EG $=$ Engle-Granger $t$-test for cointegration. $\lambda$, factor loading in the ECM. BPG, Breusch-Pagan-Godfrey heteroskedasticiy test; JB, Jarque-Bera normality test, LM, Bresuch-Godfrey serial correlation LM test. FMOLS uses Newey-West automatic bandwidth selection in computing the long-run variance matrix. In the DOLS leads and lags are selected according to SIC criteria. The standard errors for the DOLS estimation are calculated using the Newey-West correction. A dummy for first oil shock in 1970s is added in ECM formulation together with a dummy for financial crisis of 2008 .

\section{Appendix A. Data appendix}

$Y=$ Real GDP; $L=$ Employment (Total economy); HKI=Human Capital Index measured as average years of education; $I R A T=$ Ratio of investment to GDP; TRADE = Sum of imports and exports as a share of GDP.

All data, excluding HKI, are taken and constructed from AMECOEUROSTAT database. HKI is taken from Barro and Lee (2010) database.

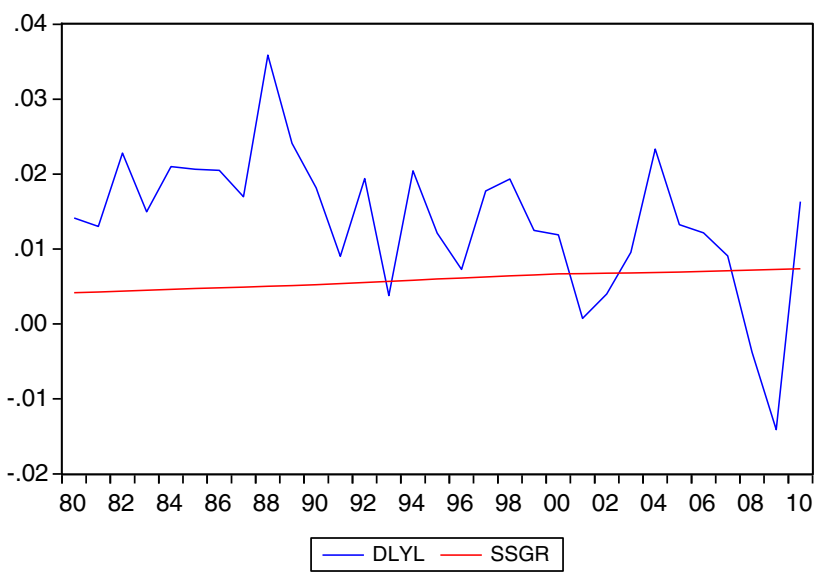

Fig. 5. Actual growth per worker and SSGR for France. 


\section{A.1. Dummy variables}

Spain. Three dummies are used for this country: two level shift dummies (1978 and 1994) and one dummy for the intensive economic crisis of 1992-1993.

Ireland. Dummy for the years 1965-1966 and dummy for the 2008-2009 financial crisis.

Italy. Dummy for years 1968-1970.

France. Dummy for the second half of 1960s (1965-1970).

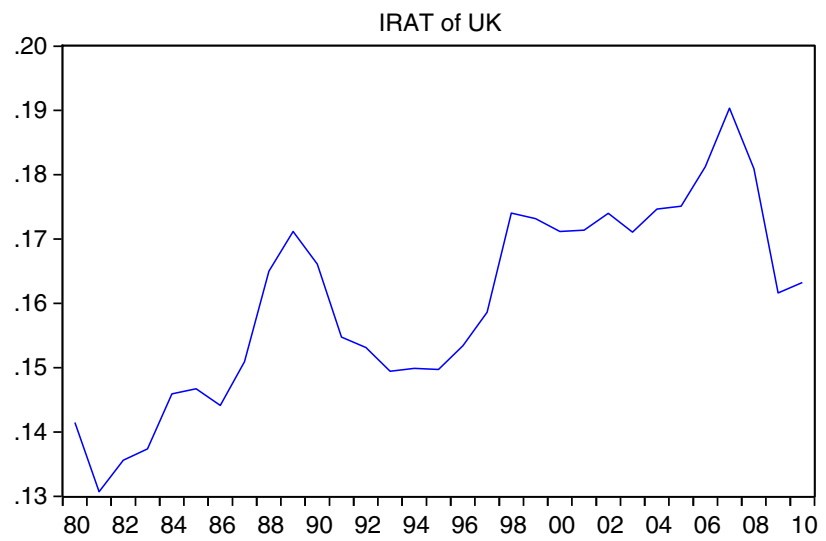

\section{References}

Barro, R.J., 1996. Determinants of Economic Growth: A Cross-country Empirical Study. NBER Working Paper No 5698. National Bureau of Economic Research, Cambridge MA.

Barro, R.J., 1998. Determinants of Economic Growth: A Cross-country Empirical Study. the MIT Press, Cambridge MA.

Barro, R., Lee, J., 2010. A new data set of education attainment in the world, 1950-2010. NBER Working Paper No. 15902. . Available at http://www.barrolee.com/data/ dataexp.htm. (Accessed 29 April 2011).

Bergheim, S., 2008. The long-run growth forecasting. Springer-Verlag, Berlin.
Boldrin, M., Conde-Ruiz, J.I., Gimenez, J.D., 2010. Eppur si muove! Spain: growing without a model. Fundacion de Estudio de Economia Aplicada, Documento de trabajo, Spain. 2010-11.

Dolado, J., Garcia-Serrano, C., Jimeno, J.F., 2002. Drawing lesson from the boom of temporary jobs in Spain. The Economic Journal 112, 270-295.

Durlauf, S.N., Johnson, P.A., Temple, J.R.W., 2005. Growth Econometrics. In: Aghion, Philippe, Durlauf, Steven (Eds.), Handbook of Economic Growth. Elsevier, pp. 555-677. edition 1 , volume 1 , chapter 8 .

Estrin, S., Holmes, P., 1983. French planning and industrial policy. Journal of Public Policy $3,131-148$.

Gonzalo, J., 1994. Five alternative methods of estimating long-run equilibrium relationships. Journal of Econometrics 60, 203-233.

Greiner, A., Semmler, W., Gong, G., 2005. The forces of economic growth: a time series perspective. Princeton University Press, Princeton, NJ.

Jones, C.I., 1995. Time-series tests of endogenous growth-models. Quarterly Journal of Economics 110, 495-525.

Levine, R., Renelt, D., 1992. A sensitivity analysis of cross-country growth regressions. The American Economic Review 82, 942-963.

Modigliani, F., Padoa Schioppa, F., Rossi, N., 1986. Aggregate unemployment in Italy, 1960-1983. Economica 53, 245-173.

O'Sullivan, K.P.V., Kennedy, T., 2010. What caused the Irish banking crisis? Journal of Financial Regulation and Compliance 18, 224-242.

Paradiso, A., Rao, B.B., 2011. How to offset the negative trend growth rate in the Italian economy? Applied Economics Letters. doi:10.1080/13504851.2010.543066 iFirst.

Phillips, C.B., Hansen, B.E., 1990. Statistical inference in instrumental variables regression with I(1) processes. Review of Economic Studies 57, 99-125.

Pisani-Ferry, J., 2003. The Surprising French Employment Performance: What Lessons? Cesifo Working Paper No. 1078. .

Rao, B.B., 2010a. Estimates of the steady state growth rates for selected Asian countries with an endogenous growth framework. Economic Modelling 26, 1012-1017.

Rao, B.B., 2010b. Time-series econometrics of growth-models: a guide for applied economists. Applied Economics 42, 73-86.

Rao, B.B., Cooray, A., 2011. How useful is growth literature for policies in the developing countries? Applied Economics. doi:10.1080/00036846.2010.517188 iFirst.

Rao, B.B., Vadlamannati, K.C., 2011a. Globalization and growth in the low income African countries with the extreme bounds analysis. Economic Modelling 28, 795-805.

Rao, B.B., Vadlamannati, K.C., 2011b. The level and growth effects of human capital in India. Applied Economics Letters 18, 59-62.

Schindler, M., 2009. The Italian Labor Market: Recent Trends, Institutions and Reform Option. IMF Working Paper No. 09/47.

Solow, R., 1956. A contribution to the theory of economic growth. Quarterly Journal of Economics 70, 65-94.

Solow, R., 1957. Technical change and aggregate production function. The Review of Economics and Statistics 39, 312-320.

Stock, J., Watson, M., 1993. A simple estimator of cointegrating vectors in higher order integrated systems. Econometrica 61, 783-820. 